CLINICAL STUDY

\title{
Q192R polymorphism of the paraoxonase-1 gene as a risk factor for obesity in Portuguese women
}

\author{
Luísa Veiga $^{1, *}$, José Silva-Nunes ${ }^{1,2, *}$, Alice Melão ${ }^{1}$, Ana Oliveira ${ }^{1}$, Leone Duarte ${ }^{2}$ and Miguel Brito ${ }^{1}$ \\ ${ }^{1}$ Escola Superior de Tecnologia de Saúde de Lisboa, Avenida D. João II, lote 4.69.01, Parque das Nações, 1990-096 Lisboa, Portugal and ${ }^{2}$ Endocrinology \\ Department, Curry Cabral Hospital, 1069-166 Lisbon, Portugal
}

(Correspondence should be addressed to L Veiga; Email: luisa.veiga@estesl.ipl.pt)

*(L Veiga and J Silva-Nunes contributed equally to this work)

\begin{abstract}
Introduction: Obesity became a major public health problem as a result of its increasing prevalence worldwide. Paraoxonase-1 (PON1) is an esterase able to protect membranes and lipoproteins from oxidative modifications. At the PON1 gene, several polymorphisms in the promoter and coding regions have been identified. The aims of this study were i) to assess PON1 L55M and Q192R polymorphisms as a risk factor for obesity in women; ii) to compare PON1 activity according to the expression of each allele in L55M and Q192R polymorphisms; iii) to compare PON1 activity between obese and normal-weight women.

Materials and methods: We studied 75 healthy $(35.9 \pm 8.2$ years $)$ and 81 obese women $(34.3 \pm 8.2$ years). Inclusion criteria for obese subjects were body mass index $\geq 30 \mathrm{~kg} / \mathrm{m}^{2}$ and absence of inflammatory/neoplasic conditions or kidney/hepatic dysfunction. The two PON1 polymorphisms were assessed by real-time PCR with TaqMan probes. PON1 enzymatic activity was assessed by spectrophotometric methods, using paraoxon as a substrate.

Results: No significant differences were found for PON1 activity between normal and obese women. Nevertheless, PON1 activity was greater $(P<0.01)$ for the RR genotype (in Q192R polymorphism) and for the LL genotype (in L55M polymorphism). The frequency of allele R of Q192R polymorphism was significantly higher in obese women $(P<0.05)$ and was associated with an increased risk of obesity (odds ratio $=2.0-95 \%$ confidence interval $(1.04 ; 3.87)$ ).

Conclusion: L55M and Q192R polymorphisms influence PON1 activity. The allele R of the Q192R polymorphism is associated with an increased risk for development of obesity among Portuguese Caucasian premenopausal women.
\end{abstract}

European Journal of Endocrinology $164213-218$

\section{Introduction}

Serum paraoxonase-1 (PON1, E.C.3.1.8.1) is a glycosylated protein of 355 amino acids, with a molecular mass of 43-47 kDa. It is synthesized by the liver and secreted into the blood, where it circulates in association with high-density lipoprotein cholesterol (HDLc) $(1,2)$.

PON1 is a calcium-dependent esterase known for its ability to hydrolyze active metabolites of several organophosphates $(3,4)$. Its primary physiological role is the protection of low-density lipoprotein cholesterol (LDLc) and HDLc from oxidative modifications through enzymatic hydroxylation of oxidized phospholipids $(1,4-6)$.

The enzymatic activity of PON1 varies widely among healthy humans, and it has been suggested that subjects with low PON1 activity may have a greater risk of developing diseases in which oxidative damage and lipid peroxidation are involved $(2,3,7)$. Several studies have demonstrated that the antioxidant activity of PON1 prevents oxidative stress mechanisms involved in pathophysiological processes associated with atherosclerosis and diabetes mellitus, among other common pathologies (8-11).

PON1 activity is modulated by environmental compounds and lifestyle, but also by genetic polymorphisms (7, 12). Human PON1 gene is coded on chromosome 7q21.3-22.1, and several polymorphisms have been identified on its promoter and coding regions. Two polymorphisms in the coding region of PON1 gene have been identified and widely studied: non-synonymous amino acid substitution $\mathrm{Gln}^{192} \rightarrow \operatorname{Arg}(\mathrm{Q} 192 \mathrm{R})$ and $\mathrm{Leu}^{55} \rightarrow$ Met (L55M) $(12,13)$. The presence of each of these polymorphisms has shown to lead to different PON1 phenotype.

The presence of L55M (rs854560) has been associated with changes in the concentration of the enzyme but small effects on its activity. On the other hand, the polymorphism Q192R (rs662) leads to different PON1 enzymatic activity behavior dependent of the isoenzyme that is present (4). These polymorphism-dependent 
changes in the PON1 phenotype have been related to several pathological states such as diabetes mellitus $(14,15)$, coronary disease $(16,17)$, and stroke $(18,19)$.

Obesity is a known risk factor for type 2 diabetes, dyslipidemia, hypertension, and atherosclerosis. Several studies have demonstrated an increase in oxidative stress in obese subjects, namely with a significantly higher susceptibility to lipid peroxidation (20). This pathophysiological mechanism has been implicated in the development of several comorbidities $(21,22)$.

Although PON1 expression has been associated with an obesity-related phenotype (23), less is known about the importance of this enzyme in the predisposition for the development of obesity. To clarify this relationship, we have studied the interaction between body mass index (BMI), PON1 activity, and Q192R and L55M polymorphisms.

Studying a population of obese and normal-weight Portuguese Caucasian premenopausal women, we intended to assess PON1 L55M and Q192R polymorphisms as a risk factor for obesity. Secondarily, we compared PON1 activity according to the expression of each allele (in both polymorphisms) and between the two groups of women.

\section{Methods}

\section{Subjects}

The obese group consisted of 81 obese Caucasian premenopausal women, who attended the obesity outpatient clinic at the Curry Cabral Hospital (Lisbon, Portugal). Their age ranged from 18 to 50 years old, and their BMI was $\geq 30 \mathrm{~kg} / \mathrm{m}^{2}$. All of them exhibited a $<10 \%$ variation in their body weight in the previous year.

The control group consisted of 75 healthy Caucasian premenopausal women, who either attended a routine health check or belonged to the health care staff of Curry Cabral Hospital. Their age ranged from 18 to 50 years old, BMI from 18.5 to $24.9 \mathrm{~kg} / \mathrm{m}^{2}$, and exhibiting $<10 \%$ variation on their body weight in the previous year.

Although all women, obese and controls, presented in a fertile status, no one was pregnant or had been pregnant in the preceding 12 months. We considered only women without previous diagnosis of any acute/ chronic conditions (except obesity for the obese group).
No woman was on any pharmacological regimen, except for oral contraceptives.

The study was conducted following the approval of the institutional scientific and ethical boards, and an informed consent was obtained from all participants.

\section{Clinical evaluation}

Each woman was anthropometrically characterized in terms of BMI, waist circumference, waist:hip ratio, and total body fat mass assessed by bioelectrical impedance (Tanita TBF-300A, Tanita Europe B.V., Hoofddorp, The Netherlands).

\section{Sample collection}

A fasting venous blood was collected from patients and controls. Serum samples were obtained by low-speed centrifugation and stored at $-80^{\circ} \mathrm{C}$ in an ultra-freezer, and thawed just before each assay. For genetic analysis, total blood was collected and stored at $-20{ }^{\circ} \mathrm{C}$.

\section{Assessment of PON1 activity}

PON1 activity assay used paraoxon (O,O-diethylp-nitrophenylphosphate; Sigma-Aldrich) as a substrate, following the rate of generation of p-nitrophenol (24). Spontaneous paraoxon hydrolysis was subtracted.

PON1 activity was initiated by adding serum samples to a reactive mixture containing $100 \mathrm{mM}$ Tris- $\mathrm{HCl}$ buffer ( $\mathrm{pH} \mathrm{8.0),} 2 \mathrm{mM} \mathrm{CaCl}_{2}$, and $2 \mathrm{mM}$ paraoxon. The reaction was followed at $412 \mathrm{~nm}$ at $25^{\circ} \mathrm{C}$, with the use of He $\lambda$ ios $\beta$ u.v.-Vis v2.04 spectrophotometer. Enzyme activity was calculated with a molar extinction coefficient of 18 290/M per cm.

\section{Analysis of L55M and Q192R polymorphisms}

Genomic DNA was isolated from white blood cells by phenol extraction. Genotyping was done through realtime PCR with TaqMan probes, using iCycler iQ Multicolor Real-Time PCR Detection System (Bio-Rad).

The design of the primers and probes (Table 1) was done using the software Beacon Designer (Primer

Table 1 Technical characterization of the primers and probes for real-time PCR genotyping for paraoxonase-1 polymorphisms.

\begin{tabular}{lll}
\hline & Sequence & \\
\hline Probes & & Fluorophore \\
192-Q & 5'-TCTCCCAGGATTGTAAGTAGGGGT-3' $^{\prime}$ & FAM \\
$192-\mathrm{R}$ & 5'-TCTCCCAGGATCGTAAGTAGGGGT-3' $^{\prime}$ & TET \\
$55-\mathrm{M}$ & 5'-CGCGATCGGCTCTGAAGACATGGAGATACTGGATCGCG-3' $^{\prime}$ & TET \\
$55-\mathrm{5}$ & 5'-CGCGATCGGCTCTGAAGACTTGGAGATACTGGATCGCG-3' $^{\prime}$ & FAM \\
Primers & & Polymorphism \\
Forward & 5'-GAGCACTTTTATGGCACAAA-3' $^{\prime}$ & Q192R \\
Reverse & 5'-TAGTAGACAACATACGACCAC-3' $^{\prime}$ & Q192R \\
Forward & 5'-GTGAGGTGTGATAAAGAAATGG-3' $^{\prime}$ & L55M \\
Reverse & $5^{\prime}$-AAAGAAAACACTCACAGAGC-3' & L55M \\
\hline
\end{tabular}


Biosoft International, Palo Alto, CA, USA). Primers and probes were acquired to Thermo Company (Whatman BioScience, Newton, MA, USA).

For the study of both polymorphisms, we used TaqMan Universal PCR Master Mix (Applied Biosystems) with primers forward and reverse (300 nM) and probes FAM and TET (250 and $150 \mathrm{nM}$ respectively). Amplification steps were $95^{\circ} \mathrm{C}$ for $10 \mathrm{~min}$, followed by 50 cycles at $92{ }^{\circ} \mathrm{C}$ for $15 \mathrm{~s}$ and $60{ }^{\circ} \mathrm{C}$ for $1 \mathrm{~min}$.

\section{Statistical analysis}

Comparisons between the groups were made by Student's t-test. Odds ratio (OR) analysis was performed using binary logistic regression adjusted for age. Interaction between the polymorphisms and PON1 activity was evaluated by ANOVA test. PON1 allelic polymorphisms and genotypic distributions were analyzed by $\chi^{2}$ test.

All determinations were performed using SPSS software, version 16.0 (Somers, NY, USA).

\section{Results}

The characteristics of the obese and control groups are depicted in Table 2. The groups were well matched for age but, as expected, were significantly different concerning all the anthropometric parameters.

No significant difference in PON1 activity was observed between control and study populations. A significant correlation between PON1 activity and BMI was presented in the obese group $(P=0.017 ; r=0.84)$, but not in the control one. Nevertheless, no correlations of PON1 activity were observed with waist circumference, waist:hip ratio, and total body fat mass $(P>0.05)$.

Table 2 Characterization of the obese and control groups included in the study. Values are represented as mean \pm s.D.

\begin{tabular}{lccr}
\hline & $\begin{array}{c}\text { Control } \\
\text { group }\end{array}$ & $\begin{array}{c}\text { Study } \\
\text { group }\end{array}$ & $\boldsymbol{P}$ value \\
\hline$n$ & 75 & 81 & \\
Age (years) & $35.9 \pm 8.2$ & $34.3 \pm 8.2$ & 0.23 \\
BMl (kg/m²) & $21.5 \pm 1.8$ & $43.1 \pm 8.5$ & $<0.001$ \\
Waist circumference (cm) & $71.6 \pm 5.7$ & $117.8 \pm 15.7$ & $<0.001$ \\
Waist/hip ratio & $0.74 \pm 0.05$ & $0.88 \pm 0.07$ & $<0.001$ \\
Fat mass (\%) & $25.1 \pm 4.5$ & $47.4 \pm 5.3$ & $<0.001$ \\
Systolic blood pressure & $108.7 \pm 13.6$ & $124.3 \pm 17.5$ & $<0.001$ \\
$\quad$ (mmHg) & & & \\
Diastolic blood pressure & $69.4 \pm 9.8$ & $79.9 \pm 11.2$ & $<0.001$ \\
$\quad$ (mmHg) & & & \\
Glycemia (mg/dl) & $83.0 \pm 6.8$ & $90.7 \pm 21.9$ & $<0.001$ \\
HbAlc (\%) & $5.3 \pm 0.3$ & $5.7 \pm 0.9$ & 0.002 \\
Triglycerides (mg/dl) & $77.8 \pm 27.8$ & $123.0 \pm 80.9$ & $<0.001$ \\
Total cholesterol (mg/dl) & $173.0 \pm 28.8$ & $184.9 \pm 33.3$ & 0.017 \\
HDL-cholesterol (mg/dl) & $67.6 \pm 14.6$ & $51.2 \pm 11.7$ & $<0.001$ \\
LDL-cholesterol (mg/dl) & $108.0 \pm 26.8$ & $118.7 \pm 27.8$ & 0.014 \\
High-sensitivity C-reactive & $0.23 \pm 0.3$ & $0.95 \pm 0.82$ & $<0.001$ \\
$\quad$ protein (mg/dl) & & & \\
Women on oral & $42.7 \%$ & $45.7 \%$ & 0.751 \\
$\quad$ contraceptives (\%) & & & \\
\hline
\end{tabular}

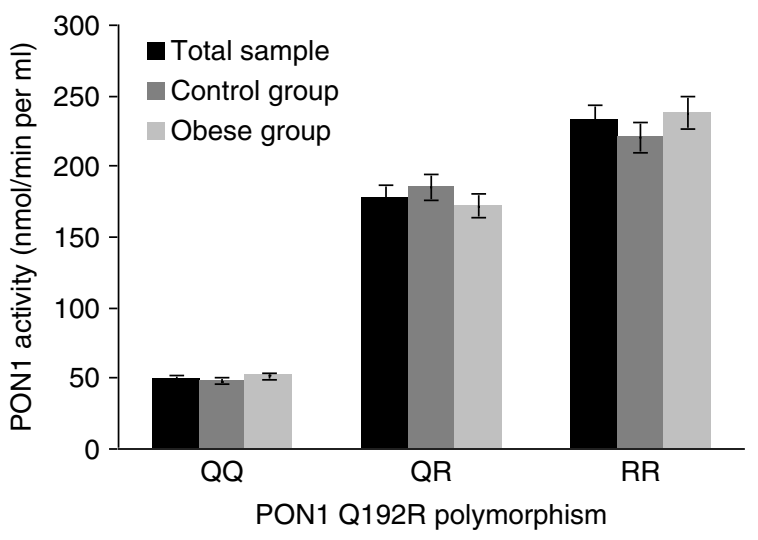

Figure 1 Serum PON1 activity in control and study populations according to the presence of different genotypes of the Q192R polymorphism $(P<0.01$ with respect to the other two genotypes, for the same population).

The two polymorphisms are in linkage disequilibrium $(P<0.001)$. There is statistical linkage and physical linkage, as they are in the same chromosome.

When we analyzed the activity of PON1, according to the polymorphisms L55M and Q192R of PON1 gene, there were significant differences in enzymatic activity between genotypes. For the Q192R polymorphism (Fig. 1), we found that the PON1 activity was significantly higher in the presence of the genotype RR and minor for QQ, with QR heterozygotes showing an intermediate activity $(P<0.01)$. For polymorphism L55M (Fig. 2), a similar profile was verified: higher PON1 activity for genotype LL, lower PON1 activity for MM genotype, and intermediate PON1 activity for the heterozygotes ML $(P<0.01)$.

The polymorphism Q192R was in accordance with the Hardy-Weinberg equilibrium in both groups. The L55M polymorphism was in accordance with the Hardy-Weinberg equilibrium in the obese group, but not in the control one, where it presented a higher prevalence of LL homozygotes $(P<0.05$; Table 3$)$. Nevertheless, when we analyzed the differences between the allelic and genotypic distribution of the L55M polymorphism, no significant dissimilarity was observed (Table 3). Conversely, the polymorphism Q192R showed significant differences in allelic and genotypic distributions between the control and obese populations $(P<0.05)$, with an increased frequency of the $\mathrm{R}$ allele in the obese group (Table 3).

OR analysis was performed for both Q192R and L55M PON1 polymorphisms (Table 4). For the L55M polymorphism, no significant influence was shown in obesity $(P>0.05)$, neither in genotypic nor in the allelic form. The genotypic expression of the Q192R polymorphism did not represent a significant risk for the development of obesity (Table 4). Nevertheless, the presence of the $\mathrm{R}$ allele $(\mathrm{QR}+\mathrm{RR})$ represented a twofold 


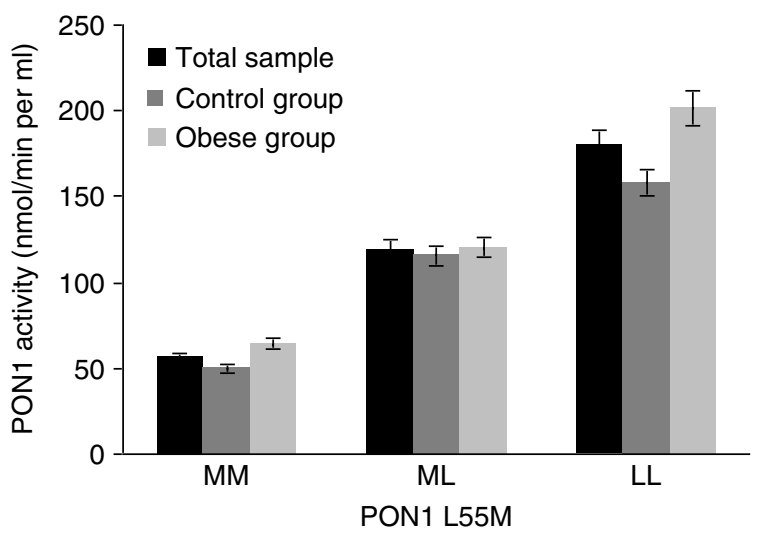

Figure 2 Serum PON1 activity in control and study populations according to the presence of different genotypes of the L55M polymorphism $(P<0.01$ for MM genotype with respect to the other two genotypes, for the same population).

(95\% confidence interval (CI): 1.04-3.87) increased risk for obesity.

No synergetic effect was observed in PON1 enzymatic activity or in obesity risk when we combined the two polymorphisms of PON1 gene.

\section{Discussion}

In Portugal, the prevalence of overweight and obesity has increased throughout the last decade, increasing to more than half of the adult population (25), in accordance with obesity epidemics worldwide. Many of the metabolic pathways and interactions related to the genesis of obesity are still unknown. That makes this disease one of the major challenges of the 21st century both in the clinical and in the investigational fields.

PON1 is an antioxidant enzyme that has been related to several pathophysiological conditions, mainly diseases associated with oxidative stress unbalanced status. Two main common polymorphisms in the

Table 3 Allelic and genotypic distributions of Q192R and L55M polymorphisms for the participant populations ${ }^{\mathrm{a}}$.

\begin{tabular}{lccc}
\hline & $\begin{array}{c}\text { Obese } \\
\text { population }\end{array}$ & $\begin{array}{c}\text { Control } \\
\text { population }\end{array}$ & $\boldsymbol{P}$ value \\
\hline Q192R & & & \\
QQ & $27(33.3 \%)$ & $37(50 \%)$ & 0.038 \\
QR & $40(49.4 \%)$ & $30(40.5 \%)$ & \\
RR & $14(17.3 \%)$ & $7(9.5 \%)$ & \\
Q & $94(0.58)$ & $104(0.703)$ & 0.033 \\
R & $68(0.42)$ & $44(0.297)$ & \\
L55M & & & \\
MM & $11(13.6 \%)$ & $16(21.6 \%)$ & 0.828 \\
ML & $39(48.1 \%)$ & $26(35.2 \%)$ & \\
LL & $31(38.3 \%)$ & $32(43.2 \%)$ & 0.809 \\
M & $61(0.38)$ & $58(0.39)$ & \\
L & $101(0.62)$ & $90(0.61)$ & \\
\hline
\end{tabular}

aValues represent the number of cases (frequency).
Table 4 Odds ratio analysis for the studied PON1 polymorphisms.

\begin{tabular}{lll}
\hline Polymorphisms & Odds ratio $(95 \% \mathrm{Cl})$ & $\boldsymbol{P}$ value \\
\hline Q192R & 1 & \\
QQ & $1.9(0.95-1.80)$ & 0.069 \\
QR & $2.5(0.86-7.06)$ & 0.091 \\
RR & 1 & - \\
QQ & $2.0(1.04-3.87)$ & 0.036 \\
QR + RR & & \\
L55 & 1 & - \\
MM & $2.2(0.89-5.64)$ & 0.085 \\
ML & $1.4(0.55-3.49)$ & 0.483 \\
LL & 1 & - \\
MM & $1.8(0.76-4.14)$ & 0.186 \\
ML + LL &
\end{tabular}

${ }^{\mathrm{a}}$ Odds ratio was calculated using binary logistic regression adjusted for age.

coding region of the PON1 gene have been identified, Q192R and L55M. They have been recognized by some authors as genetic susceptibility factors for the development of some diseases $(13,26)$.

In this study, no significant difference in PON1 activity was observed between obese and normal-weight women. So, PON1 activity seems to have no direct influence on the development of obesity. These results could be due to the fact that PON1 activity is modulated by several different factors (7), leading to a wide variability in PON1 activity among individuals. However, it was possible to determine a correlation between PON1 activity and BMI, as already reported by other authors (25).

When we analyzed the PON1 activity according to the L55M and Q192R polymorphisms, it was possible to verify that the LL and RR genotypes respectively lead to a significant increase in the enzymatic activity of PON1 in control and obese populations. Previous studies have reported similar results in type 2 diabetes mellitus (14) and cardiovascular diseases (27). This behavior may be due to structural change promoted by the polymorphism or changes in affinities to the substrate of each isoenzyme (28).

It was possible to observe that the $\mathrm{L} 55 \mathrm{M}$ polymorphism showed a deviation on the genotypic distribution, which led to an increased number of homozygote LL in the control population. However, these findings were inconclusive because L55M polymorphism was not found as a predictive risk factor for obesity. Further studies should be carried out to determine the importance of the LL genotype in obesity.

For the Q192R polymorphism, there was a prevalence of the $\mathrm{R}$ allele in the obese population. Through OR analysis, we could demonstrate that this allele was actually a risk factor for obesity per se which lead to a twofold increase risk for the development of obesity in women.

It seems contradictory that higher PON1 activity is associated with a higher risk of obesity. Nevertheless, recent studies have shown that obesity is characterized by a reduced redox state in adipose tissue, which would 
promote a deleterious pro-adipogenic process (29). This might indicate that if an elevated PON1 activity is present, it means that it is actually a higher redox state in the body. In this setting, adipogenic process would be activated and obesity would be promoted.

The major contribution of this study is that we demonstrate a direct influence of Q192R PON1 polymorphism as a risk factor for obesity.

\section{Declaration of interest}

The authors declare that there is no conflict of interest that could be perceived as prejudicing the impartiality of the research reported.

\section{Funding}

This work was funded by an Abbott/Portuguese Society of Endocrinology, Diabetes and Metabolism grant for investigation in obesity.

\section{References}

1 James RW \& Deakin SP. The contribution of high density lipoprotein apolipoproteins and derivatives to serum paraoxonase- 1 activity and function. Advances in Experimental Medicine and Biology 2010 660 173-181. (doi:10.1007/978-1-60761-350-3_16)

2 Costa LG, Vitalone A, Cole TB \& Furlong CE. Modulation of paraoxonase (PON1) activity. Biochemical Pharmacology 200569 541-550. (doi:10.1016/j.bcp.2004.08.027)

3 Bhattacharyya T, Nicholls SJ, Topol EJ, Zhang R, Yang X, Schmitt D, Fu X, Shao M, Brennan DM, Ellis SG, Brennan ML, Allayee H, Lusis AJ \& Hazen SL. Relationship of paraoxonase 1 (PON1) gene polymorphisms and functional activity with systemic oxidative stress and cardiovascular risk. Journal of the American Medical Association 2008299 1265-1276. (doi:10.1001/jama. 299.11.1265)

4 Costa LG, Cole TB, Jarvik GP \& Furlong CE. Functional genomic of the paraoxonase (PON1) polymorphisms: effects on pesticide sensitivity, cardiovascular disease, and drug metabolism. Annual Review of Medicine 200354 371-392. (doi:10.1146/annurev. med.54.101601.152421)

5 Soran H, Younis NN, Charlton-Menys V \& Durrington P. Variation in paraoxonase-1 activity and atherosclerosis. Current Opinion in Lipidology 200920 265-274. (doi:10.1097/MOL.0b013e 32832ec141)

6 Aviram M \& Rosenblat M. Paraoxonases 1, 2, and 3, oxidative stress, and macrophage foam cell formation during atherosclerosis development. Free Radical Biology and Medicine 200437 1304-1316. (doi:10.1016/j.freeradbiomed.2004.06.030)

7 Camps J, Marsillach J \& Joven J. Pharmacological and lifestyle factors modulating serum paraoxonase-1 activity. Mini Reviews in Medicinal Chemistry 20099 911-920.

8 van den Berg SW, Jansen EH, Kruijshoop M, Beekhof PK, Blaak E, van der Kallen CJ, van Greevenbroek MM \& Feskens EJ. Paraoxonase 1 phenotype distribution and activity differs in subjects with newly diagnosed type 2 diabetes (the CODAM Study). Diabetic Medicine 200825 186-193. (doi:10.1111/j.1464-5491. 2007.02328.x)

9 Rosenblat M, Karry R \& Aviram M. Paraoxonase 1 (PON1) is a more potent antioxidant and stimulant of macrophage cholesterol efflux, when present in HDL than in lipoprotein-deficient serum: relevance to diabetes. Atherosclerosis $2006 \mathbf{1 8 7} 74-81$. (doi:10. 1016/j.atherosclerosis.2005.08.026)

10 Rozenberg O, Shiner M, Aviram M \& Hayek T. Paraoxonase 1 (PON1) attenuates diabetes development in mice through its antioxidative properties. Free Radical Biology and Medicine 200844 1951-1959. (doi:10.1016/j.freeradbiomed.2008.02.012)
11 Mackness B, Quarck R, Verreth W, Mackness M \& Holvoet P. Human paraoxonase-1 overexpression inhibits atherosclerosis in a mouse model of metabolic syndrome. Arteriosclerosis, Thrombosis, and Vascular Biology 200626 1545-1550. (doi:10.1161/01.ATV. 0000222924.62641.aa)

12 Deakin SP \& James RW. Genetic and environmental factors modulating serum concentrations and activities of the antioxidant enzyme paraoxonase-1. Clinical Science 2004107 435-447. (doi:10.1042/CS20040187)

13 Li HL, Liu DP \& Liang CC. Paraoxonase gene polymorphisms, oxidative stress, and diseases. Journal of Molecular Medicine 2003 81 766-779. (doi:10.1007/s00109-003-0481-4)

14 Flekac M, Skrha J, Zídková K, Lacinová Z \& Hilgertová J. Paraoxonase 1 gene polymorphisms and enzyme activities in diabetes mellitus. Physiological Research 200857 717-726.

15 Hofer SE, Bennetts B, Chan AK, Holloway B, Karschimkus C, Jenkins AJ, Silink M \& Donaghue KC. Association between PON 1 polymorphisms, PON activity and diabetes complications. Journal of Diabetes and its Complications 200620 322-328. (doi:10.1016/j.jdiacomp.2005.08.008)

16 Mackness B, Davies GK, Turkie W, Lee E, Roberts DH, Hill E, Roberts C, Durrington PN \& Mackness MI. Paraoxonase status in coronary heart disease: are activity and concentration more important than genotype? Arteriosclerosis, Thrombosis, and Vascular Biology 200121 1451-1457. (doi:10.1161/hq0901.094247)

17 Regieli JJ, Jukema JW, Doevendans PA, Zwinderman AH, Kastelein JJ, Grobbee DE \& van der Graaf Y. Paraoxonase variants relate to 10-year risk in coronary artery disease: impact of a highdensity lipoprotein-bound antioxidant in secondary prevention. Journal of the American College of Cardiology 200954 1238-1245. (doi:10.1016/j.jacc.2009.05.061)

18 Can Demirdöğen B, Türkanoğlu A, Bek S, Sanisoğlu Y, Demirkaya S, Vural O, Arinç E \& Adali O. Paraoxonase/arylesterase ratio, PON1 192Q/R polymorphism and PON1 status are associated with increased risk of ischemic stroke. Clinical Biochemistry 200841 1-9. (doi:10.1016/j.clinbiochem.2007. 08.010)

19 Schiavon R, Turazzini M, De Fanti E, Battaglia P, Targa L, Del Colle R, Fasolin A, Silvestri M, Biasioli S \& Guidi G. PON1 activity and genotype in patients with arterial ischemic stroke and in healthy individuals. Acta Neurologica Scandinavica 2007116 26-30. (doi:10.1111/j.1600-0404.2006.00765.x)

20 Vincent HK \& Taylor AG. Biomarkers and potential mechanisms of obesity-induced oxidant stress in humans. International Journal of Obesity 200630 400-418. (doi:10.1038/sj.ijo.0803177)

21 Walley AJ, Blakemore AI \& Froguel P. Genetics of obesity and the prediction of risk for health. Human Molecular Genetics 200615 R124-R130. (doi:10.1093/hmg/ddl215)

22 Keaney JF Jr, Larson MG, Vasan RS, Wilson PW, Lipinska I, Corey D, Massaro JM, Sutherland P, Vita JA, Benjamin EJ \& Framingham Study. Obesity and systemic oxidative stress: clinical correlates of oxidative stress in the Framingham Study. Arteriosclerosis, Thrombosis, and Vascular Biology 200323 434-439. (doi:10.1161/01.ATV.0000058402.34138.11)

23 Kotani K, Sakane N, Sano Y, Tsuzaki K, Matsuoka Y, Egawa K, Yoshimura M, Horikawa C, Kitagawa Y, Kiso Y, Kimura S, Schulze J, Taing J \& Gugliucci A. Changes on the physiological lactonase activity of serum paraoxonase 1 by a diet intervention for weight loss in healthy overweight and obese women. Journal of Clinical Biochemistry and Nutrition 200945 329-334. (doi:10. 3164/jcbn.09-26)

24 do Carmo I, Dos Santos O, Camolas J, Vieira J, Carreira M, Medina L, Reis L, Myatt J \& Galvão-Teles A. Overweight and obesity in Portugal: national prevalence in 2003-2005. Obesity Reviews 20089 11-19. (doi:10.1111/j.1467-789X.2007.00422.x)

25 Abbott C, Mackness M, Kumar S, Boulton A \& Durrington P. Serum paraoxonase activity, concentration and phenotype distribution in diabetes mellitus and its relationship to serum lipids and lipoproteins. Atherosclerosis, Thrombosis, and Vascular Biology 199515 1812-1818. 
26 James RW. A long and winding road: defining the biological role and clinical importance of paraoxonases. Clinical Chemistry and Laboratory Medicine 200644 1052-1059. (doi:10.1515/CCLM. 2006.207)

27 van Himbergen TM, van der Schouw YT, Voorbij HA, van Tits LJ, Stalenhoef AF, Peeters PH \& Roest M. Paraoxonase (PON1) and the risk for coronary heart disease and myocardial infarction in a general population of Dutch women. Atherosclerosis 2008199 408-414. (doi:10.1016/j.atherosclerosis.2007.11.018)

28 Harel M, Aharoni A, Gaidukov L, Brumshtein B, Khersonsky O, Meged R, Dvir H, Ravelli RB, McCarthy A, Toker L, Silman I, Sussman JL \& Tawfik DS. Structure and evolution of the serum paraoxonase family of detoxifying and anti-atherosclerotic enzymes. Nature Structural and Molecular Biology $2004 \mathbf{1 1}$ 412-419. (doi:10.1038/nsmb767)

29 Galinier A, Carrière A, Fernandez Y, Carpéné C, André M, CasparBauguil S, Thouvenot JP, Périquet B, Pénicaud L \& Casteilla L. Adipose tissue proadipogenic redox changes in obesity. Journal of Biological Chemistry 2006281 12682-12687. (doi:10.1074/jbc. M506949200)

Received 19 October 2010

Accepted 15 November 2010 